\title{
Acetylsalicylic acid use in patients with acute myocardial infarction and peptic ulcer bleeding
}

\author{
Justin Cheung MD FRCPC ${ }^{1}$, Jennifer Rajala MD ${ }^{1}$, Daniel Moroz BSc ${ }^{1}$, Qiaohao Zhu MSc ${ }^{2}$, \\ Michael Stamm MD ${ }^{1}$, Gurpal Singh Sandha MBBS FRCPC ${ }^{1}$
}

J Cheung, J Rajala, D Moroz, Q Zhu, M Stamm, GS Sandha. Acetylsalicylic acid use in patients with acute myocardial infarction and peptic ulcer bleeding. Can J Gastroenterol 2009;23(9):619-623.

BACKGROUND: Acetylsalicylic acid (ASA) is used in the treatment of acute myocardial infarction (AMI) but is also a risk factor for peptic ulcer disease (PUD) bleeding.

OBJECTIVE: To determine the factors associated with continued ASA use in patients with AMI who develop PUD bleeding.

METHODS: AMI patients who developed PUD bleeding during the same hospitalization at two tertiary care hospitals in Edmonton, Alberta, between January 1999 and December 2006, were evaluated retrospectively. Multivariate analysis was used to determine predictors of the primary outcome of continued ASA use during PUD bleeding. RESULTS: A total of 102 patients were analyzed. Thirty-eight patients (37\%) were continued on ASA, while 64 (63\%) had ASA discontinued during their hospitalization. On multivariate regression analysis, significant predictors of continued ASA use included lowrisk ulcer stigmata on endoscopy (OR 3.7; 95\% CI 1.4 to 10.2; $\mathrm{P}=0.01$ ) and $\mathrm{AMI}$ requiring coronary intervention (OR 8.2; $95 \% \mathrm{CI}$ 2.1 to $32.1 ; \mathrm{P}=0.002)$. The mean $( \pm \mathrm{SD})$ blood transfusion requirement was $3.9 \pm 3.6$ units. The 30 -day rebleeding and mortality rates were $14 \%$ and $14 \%$, respectively.

CONCLUSIONS: The continued use of ASA during AMI and PUD bleeding was variable. However, patients with low-risk ulcers and those who received coronary intervention were more likely to have ASA continued during PUD bleeding. Further studies evaluating the gastrointestinal risk of immediate ASA use in AMI with acute PUD bleeding are required.

Key Words: Aspirin; Myocardial infarction; Nonvariceal bleeding; Peptic ulcer

$\Lambda$ ntiplatelet agents, such as acetylsalicylic acid (ASA), are Aimportant for the treatment of acute myocardial infarction (AMI) (1). A subset of patients with cardiovascular disease is also on maintenance ASA therapy for primary or secondary prevention (2-4). However, ASA is a well-known risk factor for peptic ulcer disease (PUD), with the potential for bleeding (5). The optimal early use of ASA in the acute setting of an AMI and concurrent PUD bleeding is unknown. Withholding ASA may prevent optimal treatment of the AMI, whereas continuing ASA may increase ulcer rebleeding.

The real-life practice of ASA use in the setting of AMI complicated by PUD bleeding is unknown (6-8). The objectives of the present study were to determine the current practices and predictors of continued ASA use in patients with AMI and concurrent PUD bleeding.

\section{L'emploi d'acide acétylsalicylique chez les patients victimes d'un infarctus aigu du myocarde qui présentent un saignement d'ulcère gastroduodénal}

HISTORIQUE : On utilise l'acide acétylsalicylique (AAS) pour le traitement de l'infarctus aigu du myocarde (IAM), mais il représente un facteur de risque à l'égard des saignements d'ulcères gastroduodénaux (UGD).

OBJECTIF : Déterminer les facteurs associés à l'emploi continu d'AAS chez les patients victimes d'un IAM qui présentent un saignement d'UGD. MÉTHODE : On a examiné de manière rétrospective les dossiers de patients victimes d'un IAM ayant présenté un saignement d'UGD au cours de la même hospitalisation dans deux centres de soins tertiaires d'Edmonton, en Alberta, entre janvier 1999 et décembre 2006. L'analyse multivariée a servi à déterminer les prédicteurs du paramètre principal associé à l'emploi continu d'AAS durant un saignement d'UGD.

RÉSULTATS : En tout, les auteurs ont analysé 102 patients. Trente-huit d'entre eux $(37 \%)$ ont continué de prendre l'AAS, tandis que $64(63 \%)$ ont cessé l'AAS durant leur hospitalisation. À l'analyse de régression multivariée, les prédicteurs importants du maintien du traitement par AAS incluaient la présence de cicatrices d'ulcères associés à un risque faible à l'endoscopie (RC 3,7; IC à $95 \% 1,4$ à 10,2; P = 0,01) et un IAM nécessitant une intervention coronarienne ( $\mathrm{RC} 8,2$; IC à $95 \%$ 2,1 à 32,1; $\mathrm{P}=0,002)$. Le nombre moyen ( \pm É. $-\mathrm{T}$.) d'unités de sang requises a été de 3,9 $\pm 3,6$. Les taux de reprise des saignements et de mortalité à 30 jours ont été respectivement de $14 \%$ et $14 \%$.

CONCLUSION : L'emploi continu d'AAS durant l'IAM et le saignement d'UGD a été variable. Toutefois, les patients présentant des ulcères associés à un risque faible et ceux qui ont subi une intervention coronarienne étaient plus susceptibles de prendre l'AAS de façon continue durant le saignement d'UGD. Il faudra approfondir la recherche sur le risque gastro-intestinal associé à l'emploi immédiat d'AAS lors d'un IAM en présence de saignements d'UGD.

\section{METHODS}

A retrospective review of patient medical records between January 1999 and December 2006 was undertaken at the University of Alberta and Royal Alexandra Hospitals (Edmonton, Alberta), two tertiary care hospitals affiliated with the University of Alberta. Patient records were considered eligible for inclusion if they had a hospitalization diagnosis of AMI and gastrointestinal bleeding or PUD bleeding based on the International Classification of Diseases - Ninth Revision coding. Patients were included if PUD bleeding (hematemesis, melena, rectal bleeding or new-onset anemia) started at least $24 \mathrm{~h}$ after the diagnosis of AMI. Patients with potential demand-ischemia AMI due to PUD bleeding (presenting with PUD bleeding before or within $24 \mathrm{~h}$ of AMI) were excluded. AMI cases were identified based on a diagnosis of myocardial

${ }^{1}$ Department of Medicine, University of Alberta Hospital, University of Alberta; ${ }^{2}$ Integrated Centre for Care Advancement through Research (iCARE), Edmonton, Alberta

Correspondence: Dr Justin Cheung, Zeidler Ledcor Centre, 130 University Campus, Edmonton, Alberta T6G 2 X8.

Telephone 780-492-8243, fax 780-492-1455, e-mail justin.cheung@ualberta.ca

Received for publication January 3, 2009. Accepted April 7, 2009 
TABLE 1

Baseline patient characteristics

\begin{tabular}{|c|c|c|c|c|}
\hline \multirow[b]{2}{*}{ Characteristic } & \multirow[b]{2}{*}{ Overall $(n=102)$} & \multicolumn{2}{|c|}{ Acetylsalicylic acid } & \multirow[b]{2}{*}{$\mathbf{P}$} \\
\hline & & Continued $(n=38)$ & Discontinued $(n=64)$ & \\
\hline Age, years (mean $\pm S D)$ & $75 \pm 10$ & $72 \pm 11$ & $76 \pm 9$ & 0.07 \\
\hline Men & $62(61)$ & $24(63)$ & $38(59)$ & 0.83 \\
\hline Hemoglobin, g/L (mean \pm SD) & $82 \pm 18$ & $86 \pm 16$ & $80 \pm 19$ & 0.10 \\
\hline Platelets, $\times 10^{9} / \mathrm{L}$ (mean \pm SD) & $235 \pm 124$ & $224 \pm 97$ & $241 \pm 137$ & 0.50 \\
\hline International normalized ratio, mean \pm SD & $1.3 \pm 0.6$ & $1.3 \pm 0.4$ & $1.2 \pm 0.8$ & 0.54 \\
\hline Acetylsalicylic acid & $57(56)$ & $19(50.0)$ & $38(59)$ & 0.30 \\
\hline Nonsteroidal anti-inflammatory drug & $28(28)$ & $14(37)$ & $14(22)$ & 0.36 \\
\hline Proton pump inhibitor & $12(12)$ & $4(11)$ & $8(13)$ & 0.76 \\
\hline Helicobacter pylori biopsy & $68(67)$ & $23(61)$ & $45(70)$ & 0.39 \\
\hline Positive for $H$ pylori & $21(21)$ & $10(26)$ & $11(17)$ & 0.30 \\
\hline Rockall score, mean \pm SD & $5.4 \pm 1.7$ & $4.9 \pm 1.7$ & $5.7 \pm 1.6$ & 0.02 \\
\hline Low-risk stigmata & $59(58)$ & $28(74)$ & $31(48)$ & 0.02 \\
\hline Killip score, mean \pm SD & $2.0 \pm 1.3$ & $2.0 \pm 1.3$ & $2.1 \pm 1.3$ & 0.71 \\
\hline ST segment elevation myocardial infarction & $23(23)$ & $13(34)$ & $10(16)$ & 0.05 \\
\hline Non-ST segment elevation myocardial infarction & $79(78)$ & $25(66)$ & $54(84)$ & 0.05 \\
\hline $\begin{array}{l}\text { Days from acute myocardial infarction to onset of peptic } \\
\text { ulcer disease bleeding, mean } \pm S D\end{array}$ & $+4.5 \pm 7.3$ & $+4.7 \pm 6.1$ & $+4.3 \pm 7.9$ & 0.79 \\
\hline
\end{tabular}

Data presented as $n$ (\%) unless specified otherwise

infarction made by a cardiologist through evaluation of clinical symptoms, elevated troponin, or creatine kinase-myocardial band and electrocardiogram. PUD bleeding cases were identified by the diagnosis stated in the gastroenterologist's endoscopy report, with no other possible cause of gastrointestinal bleeding in patients with suspected upper gastrointestinal bleeding. Patients with AMI who continued ASA without interruption for more than one day (C-ASA) were compared with patients who had ASA discontinued during their hospital stay (D-ASA). Patient characteristics, AMI and PUD management, and in-hospital outcomes were also recorded.

\section{Outcome measures}

The 30-day rebleeding rate $(9,10)$ was defined as the need for endoscopy based on clinical evidence of rebleeding (eg, hematemesis or melena, or a drop in hemoglobin of more than $20 \mathrm{~g} / \mathrm{L}$ ) within 30 days after stabilization and a diagnosis of PUD rebleeding (ie, visualization of blood in the upper gastrointestinal tract with high-risk PUD stigmata present) made by the endoscopist for an ulcer previously documented during the same hospital stay, with or without stigmata of recent hemorrhage $(11,12)$. Other outcome measures included total blood transfusions and in-hospital 30-day mortality.

\section{Ethics}

The study was approved by the University of Alberta and the institutional ethics review boards of the respective hospitals.

\section{Statistical analysis}

Statistical analysis was performed using SAS version 9.1 software (SAS Institute Inc, USA). Bivariate testing with the Fisher's exact test and Student's $t$ test were used for comparing categorical and continuous variables, respectively. A $\mathrm{P}<0.05$ (based on a two-tailed test) was considered to be statistically significant. Continuous variables were described as mean \pm SD. Multivariate logistic regression using a stepwise selection approach was used for the analysis of C-ASA versus D-ASA subjects, and the results are expressed with ORs and 95\% CIs. Covariates included in the regression analysis included age, sex, ulcer stigmata, Rockall score, endoscopic treatment, ST segment elevation myocardial infarction versus non-ST segment elevation myocardial infarction, cardiac Killip score, thrombolysis, angioplasty, coronary stent, coronary bypass grafting and cardiac drug treatment only.

\section{RESULTS}

The initial search for patients with diagnoses of both AMI and gastrointestinal bleeding produced 710 records. After manually reviewing these records, 102 patients were identified to have experienced an AMI complicated by acute PUD bleeding. Patient characteristics are presented in Table 1. Patients in the C-ASA group had a significantly lower Rockall score $(\mathrm{P}=0.02)$ and a greater proportion with low-risk ulcer stigmata than subjects in the D-ASA group $(\mathrm{P}=0.02)$.

The management of AMI is presented in Table 2. There was a higher percentage of patients in the C-ASA group than in the the D-ASA group receiving medications such as heparin $(87 \%$ $[\mathrm{n}=33]$ versus $63 \%[\mathrm{n}=40] ; \mathrm{P}=0.01)$ and glycoprotein IIb/IIIa receptor antagonist $(34 \%[n=13]$ versus $8 \%[n=5] ; P=0.001)$. There were significantly more patients undergoing angioplasty (29\% $[\mathrm{n}=11]$ versus $9 \%[\mathrm{n}=6] ; \mathrm{P}=0.01)$ and coronary stenting (40\% [n=15] versus $19 \%[n=12] ; P=0.02)$ in the C-ASA group than in the the D-ASA group. Conversely, significantly more patients received only pharmacological medical therapy $(70 \%$ $[n=45])$ in the D-ASA group than in the C-ASA group $(34 \%$ $[n=13] ; P=0.001)$. Twenty-four of 64 patients $(37 \%)$ in the D-ASA group did not have ASA reinstituted by the time of discharge.

Management strategies for treating PUD bleeding are shown in Table 3. Oral or intravenous proton pump inhibitors (PPIs) were used in all patients initially. Patients with high-risk stigmata ulcers were treated with intravenous pantoprazole infusion $80 \mathrm{mg}$, then $8 \mathrm{mg} / \mathrm{h}$ for $72 \mathrm{~h}$. PPI therapy was 
TABLE 2

Cardiac management in acute myocardial infarction patients with peptic ulcer disease bleeding

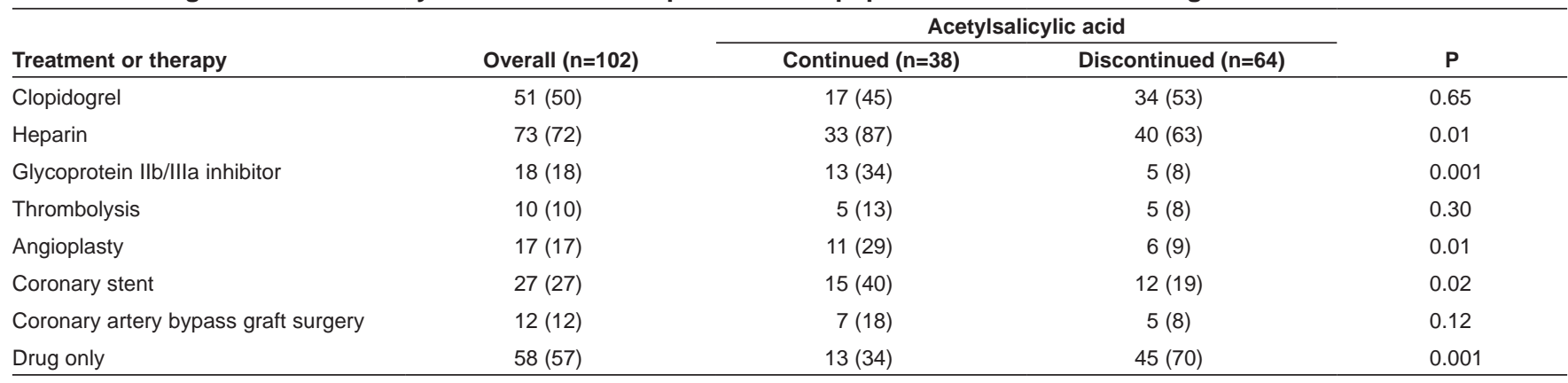

Data presented as $n$ (\%)

TABLE 3

Peptic ulcer bleeding management in acute myocardial infarction patients with peptic ulcer disease bleeding

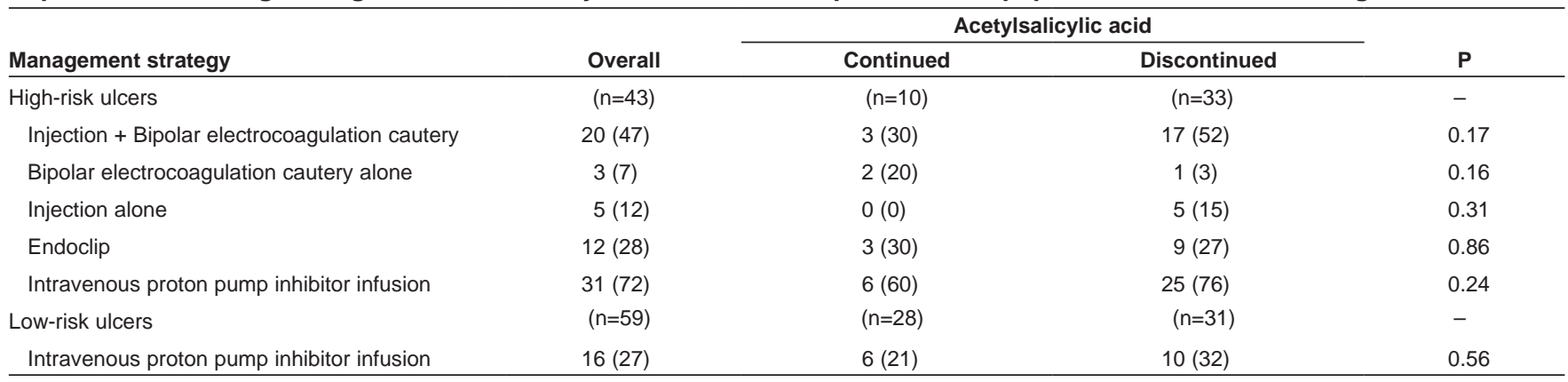

Data presented as $n$ (\%) unless specified otherwise

TABLE 4

Clinical outcomes in acute myocardial infarction patients who develop peptic ulcer disease bleeding

\begin{tabular}{|c|c|c|c|c|}
\hline \multirow[b]{2}{*}{ Outcome } & \multirow[b]{2}{*}{ Overall $(n=102)$} & \multicolumn{2}{|c|}{ Acetylsalicylic acid } & \multirow[b]{2}{*}{$\mathbf{P}$} \\
\hline & & Continued $(n=38)$ & Discontinued $(n=64)$ & \\
\hline 30-day rebleeding rate & $14(14)$ & $4(11)$ & $10(16)$ & 0.56 \\
\hline Transfusion, units (mean \pm SD) & $3.9 \pm 3.6$ & $3.3 \pm 4.0$ & $4.3 \pm 3.3$ & 0.18 \\
\hline 30-day recurrent myocardial infarction rate & $7(7)$ & $3(8)$ & $4(6)$ & 0.75 \\
\hline 30-day mortality rate & $14(14)$ & $4(11)$ & $10(16)$ & 0.56 \\
\hline Length of stay, days (mean \pm SD) & $23 \pm 19$ & $21 \pm 19$ & $24 \pm 20$ & 0.55 \\
\hline
\end{tabular}

Data presented as $n$ (\%) unless specified otherwise

continued throughout hospitalization and at discharge in all patients. None of the patients with low-risk ulcers underwent endoscopic therapy. Endoscopic therapy was performed in 40 of 43 patients (93\%) with high-risk ulcers. Endoscopic therapy was not performed in three patients with adherent clots based on the gastroenterologist's discretion at the time of the endoscopy.

The clinical patient outcomes are shown in Table 4. Two cases of rebleeding occurred in 28 ulcers with low-risk stigmata in the C-ASA group. Two cases of rebleeding in 31 ulcers with low-risk stigmata occurred in the D-ASA group.

On regression analysis, the significant predictors of C-ASA use during hospitalization included low-risk ulcer stigmata on endoscopy (OR 3.7; 95\% CI 1.4 to $10.2 ; \mathrm{P}=0.01$ ) and having undergone interventional coronary treatment (OR 8.2; 95\% CI 2.1 to $32.1 ; \mathrm{P}=0.002$ ) (Table 5).

\section{DISCUSSION}

The present study evaluated the practices of ASA use in the management of AMI accompanied by PUD bleeding at two tertiary care hospitals. We found that $37 \%$ of patients with
AMI and concurrent PUD bleeding were immediately continued on ASA therapy. The continuation of ASA was associated with lower-risk ulcers and patients who received coronary intervention.

The endoscopic finding of an ulcer with low-risk stigmata, such as a clean base or a flat, pigmented spot, was found to be an independent predictor for the immediate continuation of ASA therapy despite PUD bleeding. Previous studies $(11,12)$ in the non-AMI setting have reported that patients with lowrisk stigmata have minimal risk (less than $1 \%$ to $3 \%$ ) of rebleeding while on acid-suppressive therapy. Although it is generally recommended to discontinue ASA to allow for PUD healing, there is evidence to suggest that PUD healing continues while on PPI therapy, despite continued ASA use $(13,14)$. However, it remains unknown what the early risk of rebleeding is in the setting of AMI with immediate ongoing ASA use. There may be potential for a higher rebleeding rate due to the possible impairment of hemostasis caused by concurrent antiplatelet and anticoagulant therapy after an AMI. Additionally, AMI treatments such as clopidogrel 


\begin{tabular}{|c|c|c|c|}
\hline Factor & OR & $95 \% \mathrm{Cl}$ & $\mathbf{P}$ \\
\hline Low-risk ulcer stigmata & 3.7 & $1.4-10.2$ & 0.01 \\
\hline Coronary intervention & 8.2 & $2.1-32.1$ & 0.002 \\
\hline
\end{tabular}

may be associated with ulcer rebleeding (15). The current study suggests that in AMI patients, the endoscopic appearance of an ulcer is an important factor for physicians to consider when deciding whether to immediately continue ASA despite peptic ulcer bleeding.

An additional predictor for continued ASA use was the need for AMI coronary interventions such as balloon angioplasty, coronary stent placement or coronary bypass surgery. ASA is recommended for secondary prevention in patients with AMI (1). Additionally, patients who have received coronary interventions also have an additional risk of future rethrombosis at the site of intervention (16-18). Therefore, it is currently recommended that patients who undergo coronary stenting should initially receive double antiplatelet therapy with ASA and clopidogrel for at least one month, depending on the stent type (16). Results of the current study support the high concern for rethrombosis in the absence of ASA therapy in patients who received coronary intervention. It is important for gastroenterologists involved in the care of PUD bleeding to be aware of this competing cardiac concern after coronary stenting. The optimal use and timing of ASA in AMI and PUD bleeding remains unknown.

An unpublished interim report (14) has suggested that continued ASA therapy in patients with cardiovascular disease and PUD bleeding may not increase rebleeding and may also decrease mortality. The need for ASA in AMI patients with PUD bleeding may also have more clinical significance because a recent study (19) suggested that concurrent PPI and clopidogrel (another recommended AMI antiplatelet agent) may increase recurrent hospitalizations for coronary events. Additionally, ASA plus PPI has been shown to be superior to clopidogrel in preventing rebleeding, but the study was limited to patients who already had confirmed ulcer healing after a period in which ASA was withheld (15). Therefore, the outcomes of immediate ASA use during an AMI and PUD bleeding remains to be clarified. Although the present study

\section{REFERENCES}

1. Anderson JL, Adams CD, Antman EM, et al. ACC/AHA 2007 guidelines for the management of patients with unstable angina/ non-ST elevation myocardial infarction: A report of the American College of Cardiology/American Heart Association task force on practice guidelines. J Am Coll Cardiol 2007:50;e1-157.

2. Sanmuganathan PS, Ghahramani P, Jackson PR, et al. Aspirin for primary prevention of coronary disease: Safety and absolute benefit related to coronary risk derived from meta-analysis of randomized trials. Heart 2001;85:265-71.

3. Weisman SM, Graham DY. Evaluation of the benefits and risks of low-dose aspirin in the secondary prevention of cardiovascular and cerebrovascular events. Arch Intern Med 2002;162:2197-2202.

4. Campbell CL, Smyth S, Montalescot G, Steinhubl SR. Aspirin dose for the prevention of cardiovascular disease. A systematic review. JAMA 2007;297:2018-24.

5. Laine L. Gastrointestinal bleeding with low-dose aspirin - what's the risk? Aliment Pharmacol Ther 2006;24:897-908. recorded overall rebleeding and mortality outcomes of $14 \%$ and $14 \%$, respectively, it was not the primary aim of the study. Additionally, despite reviewing the records of two tertiary care centres, the present study was not sufficiently powered to compare rebleeding or mortality outcomes between patients who immediately continued ASA versus those who did not. A comparison of outcomes is also limited by the demonstrated selection bias between these patient groups. Finally, the rebleeding and mortality outcomes recorded in the present study represent the early 30-day outcomes that are generally reported in acute PUD bleeding studies $(9,10)$. However, outcomes after 30 days may need to be assessed to determine the longer-term effects of temporary or prolonged ASA discontinuation.

The current study investigated the practices of two tertiary care centres with acute coronary care units in which both gastroenterologists and cardiologists are involved in the management of AMI patients with PUD bleeding. In addition, emergency endoscopy and percutaneous coronary therapy was available $24 \mathrm{~h} /$ day. Practices of ASA use may be different in centres where emergency facilities are not readily available to manage potentially acute complications related to withholding or continuing ASA. Additionally, the current study may not be generalizeable to cases of demand-ischemia precipitated by anemia from acute PUD bleeding. Myocardial infarctions secondary to demand-ischemia were not included in the present study because they may have different pathophysiology, outcomes and cardiac management strategies than patients with thrombosis-related myocardial infarctions.

\section{CONCLUSION}

Immediate continuation of ASA therapy in AMI patients with concurrent PUD bleeding was variable. However, the continuation of ASA therapy during PUD bleeding was more likely in patients with low-risk ulcer stigmata who received coronary intervention. Further studies are needed to guide physicians regarding the gastrointestinal risk of immediate ASA use during treatment of AMI accompanied by PUD bleeding.

This study was presented in full, or in part, as a poster at the Annual Meeting of the Canadian Association of Gastroenterology Canadian Digestive Diseases Week, February 16-20, 2007, Banff, Alberta; and The Annual Meeting of the American College of Gastroenterology, October 12-17, 2007, Philadelphia, Pennsylvania, USA.

6. Barkun A, Bardou M, Marshall JK. Consensus recommendations for managing patients with nonvariceal upper gastrointestinal bleeding. Ann Int Med 2003;139:843-57.

7. Barkun A, Fallone CA, Chiba N, et al. Canadian clinical practice algorithm for the management of patients with nonvariceal upper gastrointestinal bleeding. Can J Gastroenterol 2004;18:605-9.

8. Palmer KR. Nonvariceal upper gastrointestinal haemorrhage guidelines. British Society of Gastroenterology Endoscopy Committee. Gut 2002;51:1-6.

9. Lau J, Sung J, Lee K, et al. Effect of intravenous omeprazole on recurrent bleeding after endoscopic treatment of bleeding. N Engl J Med 2000;343:310-16.

10. Sung J, Chan F, Lau J, et al. The effect of endoscopic therapy in patients receiving omprezole for bleeding ulcers with nonbleeding visible vessels or adherent clots. Ann Intern Med 2003;139:237-43.

11. Lai KC, WH Hui, B Wong, et al. A retrospective and prospective study on the safety of discharging selected patients with duodenal 
ulcer bleeding on the same day as endoscopy. Gastrointest Endosc 1997;45:26-30.

12. Longstreth GF, Feitelberg SP, et al. Outpatient care of selected patients with acute non-variceal upper gastrointestinal hemorrhage. Lancet 1995;345;108-11.

13. Ng FH, Wong BCY, SY Wong, et al. Clopidogrel plus omeprazole compared with aspirin plus omeprazole for aspirin-induced symptomatic peptic ulcers/erosions with low to moderate bleeding/ rebleeding risk - a single-blind randomized controlled study. Aliment Pharmacol Ther 2004;19:359-65.

14. Sung JY, Lau J, Ching J, et al. Can aspirin be reintroduced with proton pump inhibitor infusion after endoscopic hemostasis? A double-blinded randomized control trial. Gastroenterology 2006;130(Suppl 2):A44. (Abst)

15. Chan FKL, Ching JYL, Hung LCT, et al. Clopidogrel versus aspirin and esomeprazole to prevent recurrent ulcer bleeding. N Engl J Med 2005;352:238-44.

16. King SP, Smith SC, Hirshfeld JW, et al. 2007 focused update of the
ACC/AHA/SCAI 2005 guideline update for percutaneous coronary intervention. A report of the American college of cardiology/ American heart association task force on practice guidelines. J Am Coll Cardiol 2008;51:172-209.

17. Eagle KA, Guyton RA, Davidoff R, et al. American College of Cardiology. American Heart Association. ACC/AHA 2004 guideline update for coronary artery bypass graft surgery: A report of the American College of Cardiology/American Heart Association Task Force on Practice Guidelines (Committee to Update the 1999 Guidelines for Coronary Artery Bypass Graft Surgery). Circulation 2004;110:340-437.

18. Ferrari E, Benhaou M, Cerboni P, Marcel B. Coronary syndromes following aspirin withdrawal. A special risk for late stent thrombosis. J Am Coll Cardiol 2005;45;456-9.

19. Ho PM, Maddox TM, Wang L, et al. Risk of adverse outcomes associated with concomitant use of clopidogrel and proton pump inhibitors following acute coronary syndrome. JAMA 2009;301:937-44. 


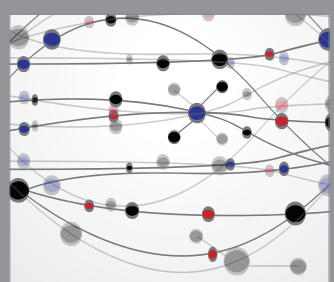

The Scientific World Journal
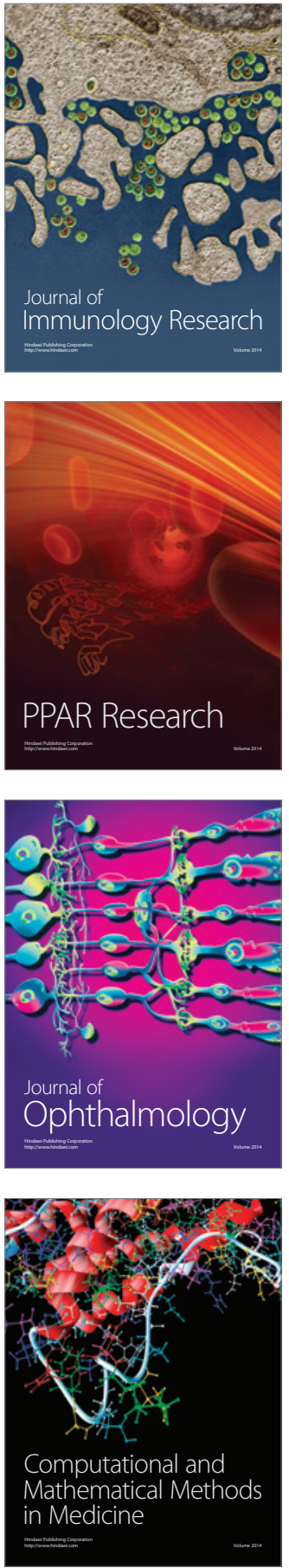

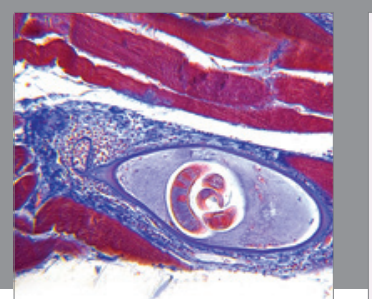

Gastroenterology Research and Practice

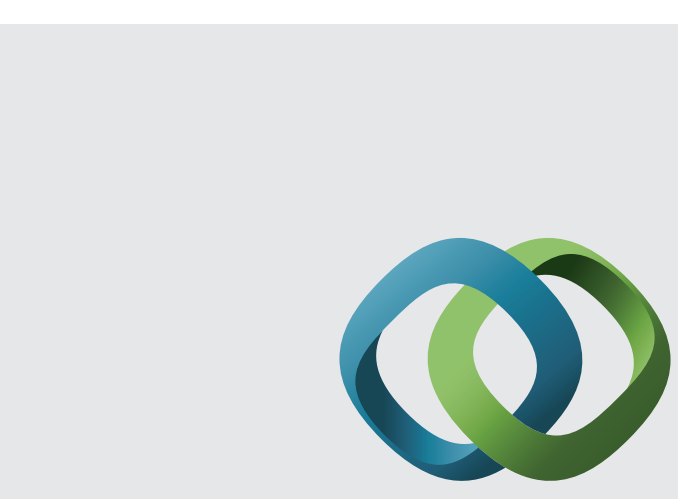

\section{Hindawi}

Submit your manuscripts at

http://www.hindawi.com
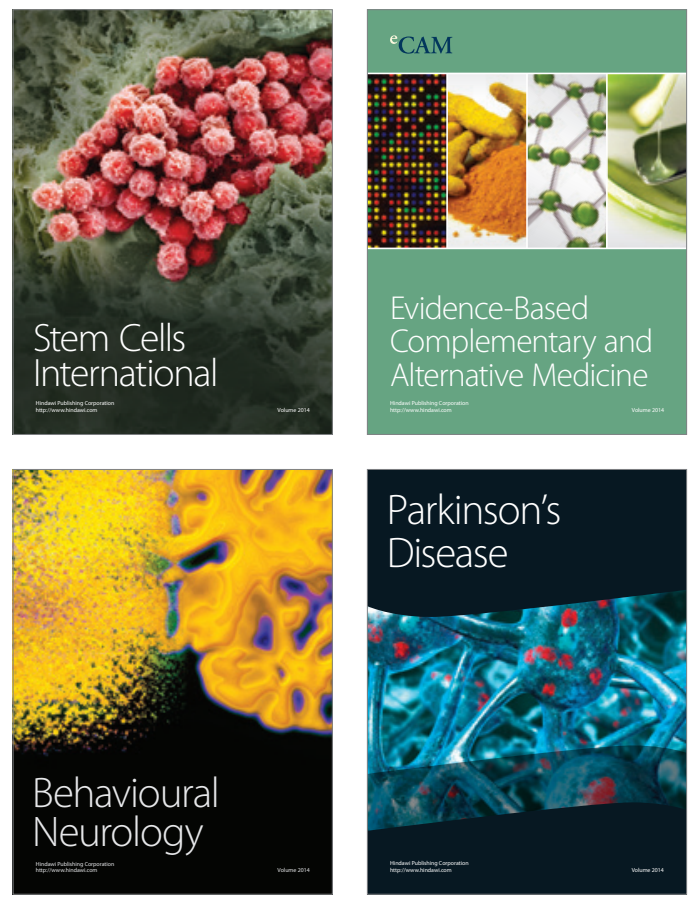
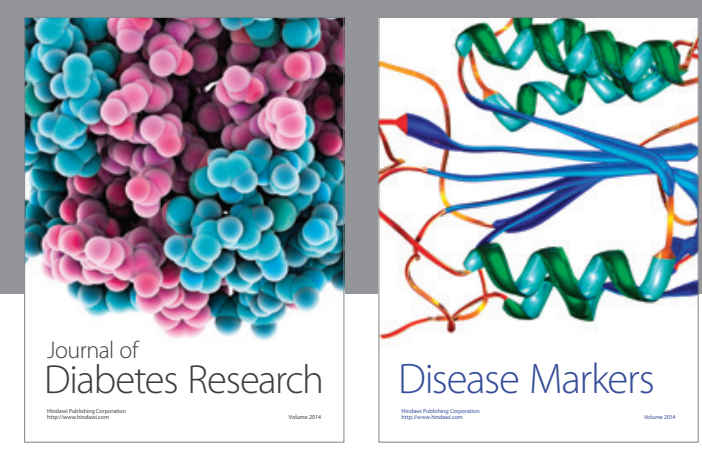

Disease Markers
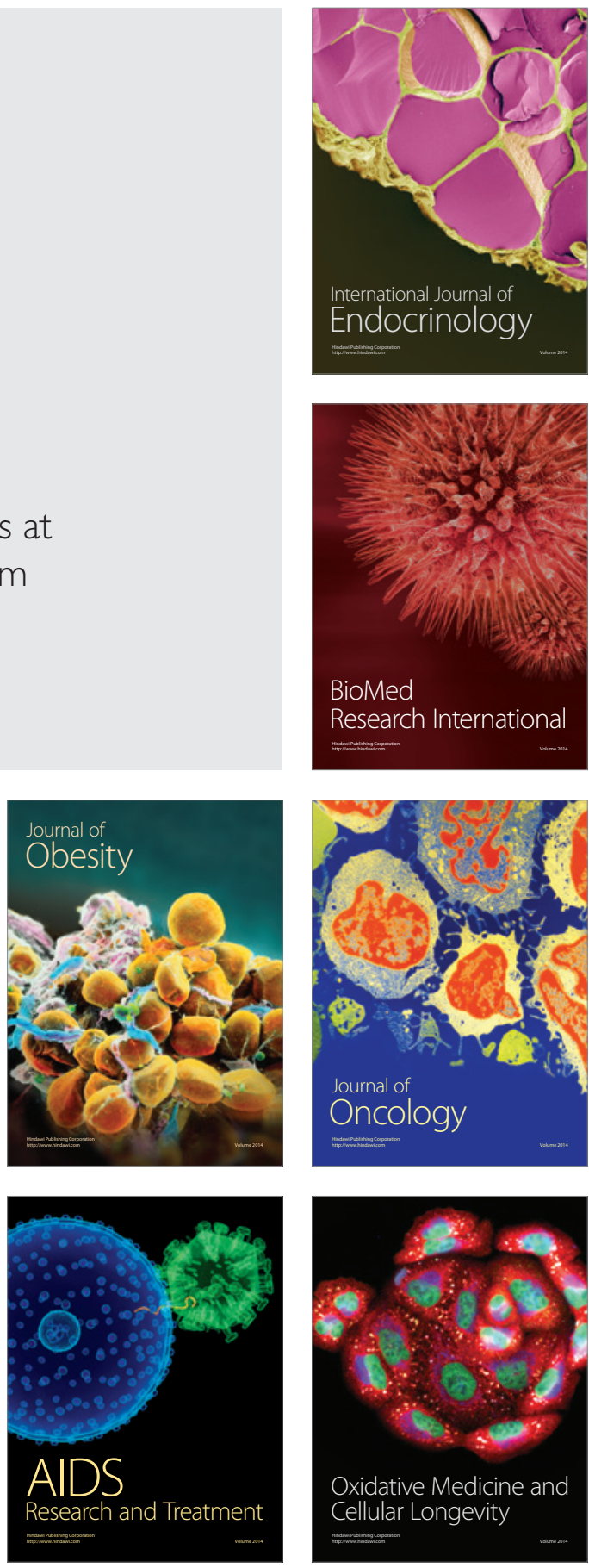